\title{
Siloxane-inorganic chemical crosslinking of hyaluronic acid - based hybrid hydrogels: Structural characterization
}

\author{
D.A. Sánchez-Téllez ${ }^{\mathrm{a}, *}$, L.M. Rodríguez-Lorenzo ${ }^{\mathrm{b}, \mathrm{c}, * *}$, L. Téllez-Jurado ${ }^{\mathrm{a}}$ \\ ${ }^{a}$ Instituto Politécnico Nacional-ESIQIE, Depto. Ing. en Metalurgia y Materiales, UPALM-Zacatenco, 07738 Mexico City, Mexico \\ ${ }^{\mathrm{b}}$ Networking Biomedical Research Centre in Bioengineering, Biomaterials and Nanomedicine, CIBER-BBN, Spain \\ ${ }^{\mathrm{c}}$ Department of Polymeric Nanomaterials and Biomaterials, ICTP-CSIC, Juan de la Cierva, 3, 28006 Madrid, Spain
}

\section{A R T I C L E I N F O}

\section{Keywords:}

Sodium hyaluronate

Hybrids

Inorganic chemical crosslinking

Siloxane matrix

\begin{abstract}
A B S T R A C T
HA-based hybrid hydrogels were successfully developed. The polysaccharide (HA) chains were chemically modified and hybridized via amidation of their carboxylic groups with aminosilane molecules. HA-polysaccharide chains were crosslinked by a 3D siloxane organic-inorganic matrix via sol-gel. The novel inorganic crosslinking network $\left(\mathrm{PDMS}-\mathrm{SiO}_{2}\right)$ provided to sodium hyaluronate (HA) strong chemical bonds, giving restriction to their natural hydrophilicity and stiffness to its structure (improved rheological properties). It was observed that synthesis conditions such as starting HA concentration solution and temperature determined gelling times, efficiency in the polysaccharide chemical modification and in crosslinking hydrolysis-condensation reactions, resulting in the siloxane organic-inorganic matrix. Drying processes influenced crosslinking in HA hybrid hydrogels, either by enhancing polycondensation reactions or inhibiting them. Room temperature-drying produced more densified hybrid structures. Freeze-drying increased porosity and surface hydroxyl groups $(-\mathrm{OH})$ resulting in more $Q_{3}$ structural units. $60^{\circ} \mathrm{C}$-drying boosted polycondensation of monodendate structural units, enhancing the formation of hybrid $D-Q$ bonds.
\end{abstract}

\section{Introduction}

The design of nontoxic materials with specific properties such as adequate degradation kinetics and good thermal stability requires the design of novel organic-inorganic hybrid materials that show, under optimum synthesis and processing conditions, synergy of properties of both organic and inorganic components. In hybrid materials, polymer networks function as organic matrices in which the inorganic components (siloxanes) work as fillers dispersed into the polymer, leading to the formation of heterogeneous organic-inorganic 3D networks with inorganic nanodomains tailoring excellent mechanical, thermal and scratch resistant properties (Sánchez-Téllez, Téllez-Jurado, \& Rodríguez-Lorenzo, 2018). Hence, exploring the rarely type of 3D inorganic chemical crosslinking of polysaccharide polymer matrixes to form Class II hybrid organic-inorganic polysaccharide-based hydrogels can guide the formation of novel materials with outstanding properties, from soft mineralized hydrogels to hard compact xerogels (SánchezTéllez, Téllez-Jurado, \& Rodríguez-Lorenzo, 2017). Inorganic components such as silica $\left(\mathrm{SiO}_{2}\right)$ chemically bonded to polysaccharides restrict their swelling degree due to their natural hydrophilicity by reducing the number of hydrophilic molecules (Heinemann, Coradin, \& Desimone, 2013). To fully comprehend these potential materials (Class II hybids), synthesized by sequential polymerization of the organic and the inorganic monomers via hydrolytic-polycondensation reactions, it is important to study the interplay between organic-inorganic components and bonds, which is to completely understand the biopolymer chemical modifications and self-assembly process and the further inorganic mechanisms during sol-gel reactions (Sánchez-Téllez, Téllez-Jurado, Rodríguez-Lorenzo et al., 2017; Sánchez-Téllez, Téllez-Jurado, Rodríguez-Lorenzo, Mazo et al., 2017; Sánchez-Téllez, Téllez-Jurado, \& Rodríguez-Lorenzo, 2015). During hybridization, sol-gel process is used as the polymerization technique, which favors the dispersion, on a molecular level, of the inorganic precursor (metal alkoxides $M(O R)_{n}$, $\mathrm{M}=\mathrm{Si}$ and $\mathrm{OR}=\mathrm{OC}_{\mathrm{n}} \mathrm{H}_{2 \mathrm{n}+1}$ ) within an organic matrix (biopolymers) to yield covalent bonds forming colloidal particles with sizes between $1-1000 \mathrm{~nm}$ kept by electrostatic and Van der Waals forces in the sol. Then, an interconnected rigid structure with polymeric chains and micro pores ( $\mathrm{gel}$ ) is conformed. Depending on the drying process, gels

\footnotetext{
* Corresponding author.

** Corresponding author at: Department of Polymeric Nanomaterials and Biomaterials, ICTP-CSIC, Juan de la Cierva, 3, 28006 Madrid, Spain.

E-mail addresses: danielatellez06@gmail.com (D.A. Sánchez-Téllez), luis.rodriguez-lorenzo@ictp.csic.es (L.M. Rodríguez-Lorenzo), ltellezj@ipn.mx (L. Téllez-Jurado).
} 
can be transformed into aerogels or xerogels (Sánchez-Téllez et al., 2018). $\mathrm{SiO}_{2}$ hybrid-type materials have been obtained mainly from alkoxysilanes and the hydrolysis of the tetraethoxysilane (TEOS), the most common precursor to form silica network in situ within an organic matrix (Sánchez-Téllez, Téllez-Jurado, \& Chávez-Alcalá, 2014, 2015; Téllez, Rubio, Rubio, Morales, \& Oteo, 2004; Téllez, Rubio, Rubio, Morales, \& Oteo, 2003). Siloxane-based hybrid materials have demonstrated to have a wide range of applications such as stimuli responsive drug delivery systems (Liu, Detrembleur, De Pauw-Gillet, Jérome, \& Duguet, 2015), flame retarded polymer based devices (Chiu et al., 2008) and antibacterial hybrids (Dastjerdi \& Montazer, 2010) since the inorganic groups introduced new properties to polymer matrices. In bio-applications, the need to develop strong hydrated polymeric-based gels that best resemble the chemical, physical and mechanical environment of ECM in connective tissue such as articular cartilage makes polysaccharide-SiO $\mathrm{S}_{2}$-based hybrid hydrogels (Sánchez-Téllez, TéllezJurado, Rodríguez-Lorenzo et al., 2017) great candidates for cartilage substitution and repair (Tchobanian, Van Oosterwyck, \& Fardim, 2019). Thus, the aims of this work are 1) to study the novel inorganic crosslinking method used to develop 3D hybrid hydrogels synthesized with sodium hyaluronate (HA) chemically modified with an aminosilane and crosslinked with an organic-inorganic siloxane structure and 2) to determine the influence of synthesis conditions on their resulting chemical, physical and morphological hybrid structures; which will help to reveal the power of the studied inorganic crosslinking approach to generate complex valuable hybrid hydrogel systems with improved properties.

\section{Experimental Procedure}

\subsection{Materials}

HA-based hybrid hydrogels were prepared in two steps: 1) chemical modification and hybridization via amidation and 2) crosslinking via sol-gel method. For the first step, the starting reagents were: 1) sodium hyaluronate oral grade $\mathrm{Mw}=193173 \mathrm{Da}$, intrinsic viscosity $0.28 \mathrm{~m}^{2} / \mathrm{kg}$ (HA, BioIberica); 2) N-(3-Dimethylaminopropil)-N'ethylcarbodiimide hydrochloride (EDC, $\mathrm{C}_{8} \mathrm{H}_{17} \mathrm{~N}_{3} \cdot \mathrm{HCl}$, Sigma-Adrich); 3) N-hydroxysuccinimide (NHS, $\mathrm{C}_{4} \mathrm{H}_{5} \mathrm{NO}_{3}$, Sigma-Aldrich); 4) 2-(N-Morpholino) ethanesulfonic acid hydrate (MES, $\mathrm{C}_{6} \mathrm{H}_{13} \mathrm{NO}_{4} \mathrm{~S} \cdot \mathrm{H}_{2} \mathrm{O}$, Sigma-Aldrich); 5) 3-aminopropyltriethoxysilane (APTES, $\mathrm{H}_{2} \mathrm{~N}\left(\mathrm{CH}_{2}\right)_{3} \mathrm{Si}\left(\mathrm{OCH}_{2} \mathrm{CH}_{3}\right)_{3}$, Sigma-Aldrich); 6) deionized water. For the second step, the starting reagents were: 1) tetraethylorthosilicate (TEOS, $\mathrm{Si}\left(\mathrm{OCH}_{2} \mathrm{CH}_{3}\right)_{4}$, SigmaAldrich); 2) hydroxyl-terminated polydimethylsiloxane (PDMS, OH-[Si $\left.\left(\mathrm{CH}_{3}\right)_{2}-\mathrm{O}\right]_{n} \mathrm{H}$, Sigma-Aldrich, $\mathrm{MW}=550$ gmol, viscosity $\left.=25 \mathrm{cSt}\right)$.

\subsection{Synthesis of the HA-based hybrid hydrogels}

The synthesis process for HA-based hybrid hydrogels starts with the preparation of a polysaccharide (HA) aqueous solution $(67 \mathrm{mg} / \mathrm{mL}$, $50 \mathrm{mg} / \mathrm{mL}, 33 \mathrm{mg} / \mathrm{mL}$ ). EDC and NHS, both acting as carboxylic acid activating agents, were added to the HA aqueous solution with magnetic stirring. After $30 \mathrm{~min}$ the accurate amount of MES and APTES were also added to the solution (Hu, Li, Zhou, \& Gao, 2011). pH value was adjusted to 6 by adding little by little MES powder, used as buffer agent. Equivalent ratios of the components HA/APTES/EDC/NHS/MES used are $1 / 1 / 1.5 / 1 / 2.5$, respectively. Then, the crosslinking of the sodium hyaluronate occurred when adding TEOS and PDMS to the solution, resulting in the formation of hybrid hydrogels with a three dimensional siloxane organic-inorganic matrix produced by sol-gel method. Weight ratios of the components APTES/TEOS/PDMS used are $0.1 / 0.1 / 0.8$, respectively. The reaction took place at $37^{\circ} \mathrm{C}$ and $40^{\circ} \mathrm{C}$ under stirring conditions for $1 \mathrm{~h}$. When the reagent addition had finished, the sols were poured into plastic containers and kept closed at room temperature $\left(\approx 25^{\circ} \mathrm{C}\right)$ for gelling and aging times during 10 days. After aging time had finished, hybrid hydrogels were processed under different conditions: 1) materials were kept under wet conditions (same conditions as in aging time) to obtain wet gels; 2) materials were freeze at $-20^{\circ} \mathrm{C}$ for $24 \mathrm{~h}$ and then freeze-dried for one week to obtain aerogels; 3) materials were dried at room temperature till all the liquids trapped inside their networks were eliminated to obtain xerogels; or 4) materials were dried at room temperature for $24 \mathrm{~h}$ and then placed into an oven and dried at $60{ }^{\circ} \mathrm{C}$ for $24 \mathrm{~h}$ to obtain dried gels. The sample code of each hybrid hydrogel is assigned according to: 1) polysaccharide concentration solution; and 2) type of drying process; e.g., $67 \mathrm{HA}-\mathbf{R T}$ hybrid hydrogel stands for $[67 \mathrm{mg} / \mathrm{ml}]$ of HA synthesized at $p H=6$ and dried at room temperature. Note: $\mathbf{F D}=$ Freeze-drying process; $\mathbf{R T}=$ Room Temperature drying process; $\mathrm{T}=60^{\circ} \mathrm{C}$ drying process.

\subsection{Characterization of the HA-based hybrid hydrogels}

Several characterization techniques were used to evaluate and analyze the HA-based hybrid hydrogels: 1) Rheology; 2) Fourier Transform Infrared Spectroscopy; 3) Raman Spectroscopy; 4) Nuclear Magnetic Resonance; 5) Thermogravimetric Analysis; 6) Scanning Electron Microscopy.

Rheological measurements of polysaccharide-based hybrid hydrogels were carried out by stress-controlled oscillatory rheometer ARG2 TA Instruments using parallel plate geometry. Sol samples were measured with a $40 \mathrm{~mm}$ diameter top plate aluminum (Al) geometry. Dynamic time sweep analysis was carried out in sol samples at $1.6 \%$ strain, $\approx 0.25 \mathrm{~N}$ normal forces, a frequency of $0.75 \mathrm{~Hz}$ and at $37^{\circ} \mathrm{C}$ and $40{ }^{\circ} \mathrm{C}$ from 0 to $5000 \mathrm{~s}$ in order to analyze sol-gel transition time.

Structural characterization of the HA-based hybrid hydrogels was performed by three spectroscopic techniques, FT-IR, Raman and MASNMR. 1) FT-IR spectra were obtained at room temperature in a Perkin Elmer Spectrum Two spectrometer coupled with an Attenuated Total Reflection, Perkin Elmer (ATR-FTIR). Spectra were recorded in transmittance mode in the range from 400 to $600 \mathrm{~cm}^{-1}$ with 16 scans and a resolution of $4 \mathrm{~cm}^{-1}$. 2) Raman spectra were carried out in a Renishaw InVia Reflex Raman system (Renishaw plc, Wotton-under-Edge, UK), consisting of a grating spectrometer with a Peltier-cooled charge-coupled device (CCD) detector, coupled to a confocal microscope. The Raman scattering was excited using a diode laser at a wavelength of $785 \mathrm{~nm}$. The laser beam was focused on the sample with a $0.85 \times 100$ microscope objective. The laser power was $160 \mathrm{~mW}$, the exposure time was three seconds and the number of accumulations for the Raman measurements was two. The spectra were processed using Renishaw WiRE 3.3 software. 3) The solid-state Magic Angle Spinning - Nuclear Magnetic Resonance (MAS-NMR) spectra were obtained with a Bruker Advance TM 200WB spectrometer equipped with a wide-mouth superconducting magnet $(89 \mathrm{~mm})$ operating at 9.4 Teslas with a frequency of $400 \mathrm{MHz}$.

Morphological characterization of the HA-based hybrid hydrogels was performed in a high resolution JEOL Scanning Electron Microscope, model JSM6701 F. The voltage was $15 \mathrm{kV}$ and the working distance was $8 \mathrm{~mm}$ to prevent samples from being degraded due to their organic-inorganic character. The analyzed samples were adhered to a copper sample holder using graphite adhesive tape. A layer of goldpalladium was deposited on the samples to make them conductive. The metal deposition was carried out with a Sputter coater Polaron SC7640 with a gold target at $40 \mathrm{~mA}$ for $90 \mathrm{~s}$.

The thermogravimetric analysis of the HA-based hybrid hydrogels was performed on dried samples in a TA instrument, model TGA Q5000 V20.13. Samples were heated from $25^{\circ} \mathrm{C}$ to $800{ }^{\circ} \mathrm{C}$ at a heating rate of $10^{\circ} \mathrm{C} / \mathrm{min}$, keeping a constant air flow of $10 \mathrm{~mL} / \mathrm{min}$.

\section{Results and discussion}

\subsection{Synthesis of the HA-based hybrid hydrogels}

A synthesis process was developed to modulate natural 




Fig. 1. Amidation of sodium hyaluronate (Na-HA) with 3-aminopropyltriethoxysilane (APTES).

hydrophilicity of HA-based hydrogels by crosslinking the polysaccharide inorganically in order to create novel organic-inorganic hybrid materials capable of having good degradation kinetics and improved rheological properties. This process allowed the hybridization and crosslinking of sodium hyaluronate (HA) with the following organic-inorganic compounds: 1) 3-aminopropyltriethoxysilane (APTES); 2) tetraethylorthosilicate (TEOS); 3) polydimethylsiloxane (PDMS). The first step is amidation of sodium hyaluronate, a reaction between amine groups $\left(-\mathrm{NH}_{2}\right)$ from APTES and carbonyl groups $\left(\mathrm{COO}^{-}\right)$from the hyaluronate by using EDC and NHS as catalysts (Hu et al., 2011), as shown in Fig. 1.

Then in a second step, a sol-gel method is used to form the 3D hybrid siloxane organic-inorganic matrix (Peña-Alonso, Rubio, \& Rubio, 2005; Peña-Alonso, Rubio, Rubio, \& Oteo, 2007; Sánchez-Téllez et al., 2015; Sánchez-Téllez, Téllez-Jurado, Rodríguez-Lorenzo et al., 2017; Sánchez-Téllez, Téllez-Jurado, Rodríguez-Lorenzo, Mazo et al., 2017; Téllez et al., 2004) used as crosslinker of the hyaluronate. In this method, the hydrolysis-condensation reactions occur among the inorganic modifier (APTES), the silica alkoxide (TEOS) and the silicone (PDMS). The modifier APTES $\left(\mathrm{NH}_{2}-\mathrm{C}_{3} \mathrm{H}_{7} \mathrm{Si}(\mathrm{OR})_{3}\right.$, where -OR corresponds to ethoxy groups $-O C_{2} H_{5}$ ) and the silica alkoxide TEOS $\left(\mathrm{Si}(\mathrm{OR})_{4}\right.$, where $\mathrm{R}$ also corresponds to ethoxy groups $-\mathrm{OC}_{2} \mathrm{H}_{5}$ ) act as precursors and tracers of silica network. During the hydrolysis reaction, the ethoxy groups (OR) from APTES and TEOS are attacked by water molecules to be hydrolyzed and form silanol ( $\mathrm{Si}-\mathrm{OH}$ )groups. Simultaneously, an ethanol molecule $\left(\mathrm{C}_{2} \mathrm{H}_{5}-\mathrm{OH}\right)$ is formed per each hydrolyzed radical. Once the hydrolysis is carried out, silanol groups $(\mathrm{Si}-\mathrm{OH})$ are condensed, leading to the condensation/alcoholysis reactions. In these reactions, water molecules are eliminated to form a dense continuous inorganic $\mathrm{SiO}_{2}$ matrix. Reaction rate of hydrolysis reactions is faster than reaction rate of condensation reactions. Condensation reactions can occur either between an ethoxy radical ( $\mathrm{Si}-\mathrm{O}-\mathrm{CH}_{2} \mathrm{CH}_{3}$ ) or a hydrolyzed radical $(\mathrm{Si}-\mathrm{OH})$ from APTES/ TEOS to form ethanol molecules or between two hydrolyzed radicals from APTES and TEOS molecules to form water molecules. The organic modification within the $\mathrm{SiO}_{2}$ network is carried out through the incorporation of PDMS, an organic modifier and network extender. Since PDMS structure is similar to silica structure by having a $\mathrm{Si}-\mathrm{O}-\mathrm{Si}$ backbone and hydroxyl terminated groups $(-\mathrm{OH})$, PDMS can condense with APTES and TEOS hydrolyzed radicals $(\mathrm{Si}-\mathrm{OH})$, extending and giving the silica network its silicone properties. Thus, chemical crosslinking of the hyaluronate (HA) is carried out through the siloxane organic-inorganic network, building up a hybrid hydrogel with a 3D matrix (Fig. 2) containing HA chains randomly distributed and stabilized by Van der Waals interactions (hydrogen bonds, electrostatic interactions, hydrophobic forces, etc.).

\subsection{Rheological characterization of the HA-based hybrid hydrogels: gelling} time

Gelling time or sol-gel transition time in HA-based hybrid hydrogels was monitored during crosslinking reactions through their rheological properties. Sol-gel transition is considered to be the intersection point $\left(G^{\prime}=G^{\prime \prime}\right)$ between storage $\left(G^{\prime}\right)$ (elastic behavior) and loss $\left(G^{\prime \prime}\right)$ (viscous behavior) moduli. Gelling time of hybrid hydrogels allowed establishing a direct relationship between sol-gel transition time and the hydrolysis-condensation reaction rate. Fig. $3 \mathbf{A}$ shows the dynamic time sweep analysis carried out in sol samples of the HA-based hybrid hydrogels in order to analyze their sol-gel transition time. It is observed that the hybrid hydrogels with higher concentration of sodium hyaluronate $(67 H A>50 H A>33 H A)$ and higher reaction temperature $\left(40^{\circ} \mathrm{C}>37^{\circ} \mathrm{C}\right)$ led to shorter gelling times. Since hyaluronate polymer chains acted as network formers faster crosslinking rates occurred. Besides, when increasing water content into the reaction system, condensation reactions among APTES-TEOS-PDMS which works as network formers, were inhibited; causing the chains to be shorter and with lower crosslinked density. Furthermore, the acidic medium, favored by the addition of MES to boost amidation, also catalyzed the hydrolysiscondensation reactions during the sol-gel reactions, improving the efficiency and the formation of linear crosslinked chains of the siloxane network (Peña-Alonso et al., 2007; Tamayo \& Rubio, 2010). After aging time, the physical appearance of hybrid hydrogels (Fig. 3B) was related to their composition and drying process. Thus, the hydrogels showed denser and stiffer organic (HA) - inorganic (siloxane $\rightarrow$ PDMS-modified $\mathrm{SiO}_{2}$ ) networks chemically crosslinked.

\subsection{Structural characterization of the HA-based hybrid hydrogels}

The infrared spectra of HA-based hybrid hydrogels are shown in Fig. 4A. The assignation of the bands was done according to literature data. Bands related to sodium hyaluronate, APTES and siloxane networks, formed during the hydrolysis-condensation reactions, could be seen in the FT-IR spectra of the HA-based hybrid hydrogels. The FT-IR spectra of the HA-based hybrid hydrogels showed four important bands, indicating the successful formation of an organic-inorganic hybrid hydrogel: 1) the band at $1560 \mathrm{~cm}^{-1}$ is assigned to the formation of the amide II bonding between the carboxyl $\mathrm{COO}^{-}$group in $\mathrm{HA}$ and the amine group in APTES (Hu et al., 2011), confirming the grafting between APTES and hyaluronate. This band is mainly assigned to bending vibrations $\delta_{N-H}$ of amide $N-H$ group establishing one hydrogen bond (Eslahi, Simchi, Mehrojoo, Shokrgozar, \& Bonakdar, 2016; Haxaire, Maréchal, Milas, \& Rinaudo, 2003); 2) the bands at $975 \mathrm{~cm}^{-1}$ and $895 \mathrm{~cm}^{-1}$ are assigned to $\mathrm{Si}-\mathrm{OH}$ groups and to asymmetric stretching $\vartheta_{a}(\mathrm{Si}-\mathrm{O})$ in $\mathrm{Si}-\mathrm{OH}$ bonds from PDMS, respectively; proving hydrolysis reactions; 3) the band at $850 \mathrm{~cm}^{-1}$ is attributed to (TEOS) $\mathrm{Si}-\mathrm{O}-\mathrm{Si}$ (PDMS) bonds, corresponding to hybrid crosslinked (Q units) $\mathrm{SiO}_{2}$ - PDMS (D units) structures, showing the incorporation of PDMS within the 3D $\mathrm{SiO}_{2}$ network; 4) the band at $790 \mathrm{~cm}^{-1}$ assigned to the silicon tetrahedron $\left[\mathrm{SiO}_{4}\right]$ and $\mathrm{Si}-\mathrm{C}$ bonds, corresponds to PDMS and APTES molecules, ensuring an inorganic crosslinking of hyaluronate (Sánchez-Téllez et al., 2015; Téllez et al., 2004). Drying process influenced the final state of hybrid hydrogels. FT-IR spectra of hybrid hydrogels dried at room temperature and $60{ }^{\circ} \mathrm{C}$ show bands in the region between $1300-900 \mathrm{~cm}^{-1}$ attributed byproducts (ethanol), unreacted intermediates (o-acylisoureas, amine-reactive-esters) and unreacted reagents. However, these bands are not present in freeze-dried hybrid hydrogels due to the conditions at which they were dried.

The Raman spectra of the HA-based hybrid hydrogels are shown in 




Fig. 2. Inorganic chemical crosslinking of hyaluronate with a siloxane organic-inorganic network to form hybrid hydrogels.

Fig. 4B. The identified bands were assigned according to literature data (Alkrad, Mrestani, Stroehl, Wartewig, \& Neubert, 2003; Cai, Neyer, Kuckuk, \& Heise, 2010; Jayes, Hard, Séné, Parker, \& Jayasooriya, 2003; Kotzianová, Rebícek, Pokorný, Hrbác, \& Velebný, 2016; Qi et al., 2016; Sánchez-Téllez, Téllez-Jurado, Rodríguez-Lorenzo et al., 2017; Sánchez-Téllez, Téllez-Jurado, Rodríguez-Lorenzo, Mazo et al., 2017; Sun, Yanagisawa, Kunimoto, Nakamura, \& Homma, 2016; Sun, Yanagisawa, Kunimoto, Nakamura, \& Homma, 2017; Tamayo \& Rubio, 2010). Several Raman bands related to sodium hyaluronate hydrogels and silica-based hybrid materials are observed in the HA-based hybrid hydrogels Raman spectra. The most important Raman scattering due to different bond vibrations related to sodium hyaluronate (HA) (Alkrad et al., 2003; Kotzianová et al., 2016), chemical modification of HA with APTES (Sun et al., 2016, 2017) and PDMS-modified $\mathrm{SiO}_{2}$ crosslinked matrix (Qi et al., 2016; Sun et al., 2016) in the HA-based hybrid hydrogels are: 1) the band at $820 \mathrm{~cm}^{-1}$ is due to stretching vibrations of $\mathrm{C}-\mathrm{O}-\mathrm{C}$ bonds from the hyaluronic acid repetitive units (D-glucuronic acid and N-acetyl-D-glucosamine, linked via alternating $\beta$ - $(1 \rightarrow$ 4) and $\beta-(1 \rightarrow 3)$ glycosidic bonds); 2) the band around $1415 \mathrm{~cm}^{-1}$ may be assigned to the bending vibration of $\mathrm{CH}_{2}$ group bonded to the $\mathrm{Si}$ atom $\left(\mathrm{Si}-\mathrm{CH}_{2}\right)$; 3) the band at $1135 \mathrm{~cm}^{-1}$ is attributed to the $\mathrm{Si}-\mathrm{O}-\mathrm{Si}$ bond-bending vibration; 4) the bands around $1036 \mathrm{~cm}^{-1}$ and $945 \mathrm{~cm}^{-1}$ are assigned to $O-S i-O$ bonds; 5) the band around $980 \mathrm{~cm}^{-1}$ is due to $\mathrm{Si}-\mathrm{OH}$ bonds. Likewise, the following bands show the correct incorporation of PDMS into the $\mathrm{SiO}_{2}$ network (Cai et al., 2010; Jayes et al., 2003; Sánchez-Téllez, Téllez-Jurado, RodríguezLorenzo et al., 2017; Sánchez-Téllez, Téllez-Jurado, Rodríguez-Lorenzo, Mazo et al., 2017; Tamayo \& Rubio, 2010): 1) the bands around $1415 \mathrm{~cm}^{-1}$ and $1265 \mathrm{~cm}^{-1}$ are assigned to the asymmetric and symmetric bending vibration of $\mathrm{CH}_{3}$ group from PDMS, respectively; 2) the band at $865 \mathrm{~cm}^{-1}$ is attributed to the symmetric rocking of $\mathrm{CH}_{3}$ from PDMS; 3) the band at $790 \mathrm{~cm}^{-1}$ is due to $\mathrm{C}-\mathrm{Si}-\mathrm{C}$ asymmetric stretching vibration and to the rocking vibration of $\mathrm{CH}_{3}$ group from PDMS; 4) the band at $707 \mathrm{~cm}^{-1}$ is due to $\mathrm{C}-\mathrm{Si}-\mathrm{C}$ symmetric stretching vibration; 5) the band at $689 \mathrm{~cm}^{-1}$ is attributed to $\mathrm{Si}-\mathrm{CH}_{3}$ symmetric rocking; 6) the band at $495 \mathrm{~cm}^{-1}$ is assigned to $O-S i-O$ bonds. Structural changes are caused by the selected drying process and the polycondensation, being also affected by the concentration of the starting
HA solution in the system. Variation on micro and nanostructure can be found in TEOS-PDMS hybrid materials when modulating water-solvent ratios (Tamayo \& Rubio, 2010). During sol sate, prior to gelation, the hydrolysis and condensation reactions occur at a certain rate; however, when gelling transition starts, the reaction rate decreases due to the reduction in the mobility of the components. Therefore, when allowing the hybrid hydrogels to age and then dried at a constant but slow rate, the hydrogel network will be reinforced through further polymerization, increasing and decreasing the intensity in Raman bands attributed to $\mathrm{Si}-\mathrm{O}-\mathrm{Si}$ bonds and $\mathrm{Si}-\mathrm{OH}$ bonds, respectively. The difference among the 67HA, 50HA and 33HA hybrid hydrogels spectra indicates that the materials are chemically crosslinked, having nanodomains rich in $\mathrm{SiO}_{2}$ and PDMS. Thus, what it is important in these hydrogels is that the inorganic phase domains, formed in the sol-gel process, are polydispersed in size and heterogeneous in chemical composition. However, by using Raman spectroscopy it is not possible to establish if PDMS is either incorporated into the hybrid network or entrapped within the hybrid hydrogel. Letting the hybrid hydrogels to dry at room temperature gives them the opportunity of polycondensation and densification of their siloxane network, but byproducts may continue to be trapped within the hydrogel structure. On the other hand, when the liquids are removed by freeze-drying process, the polycondensation of siloxane network is frozen, so it does not have the chance to get crosslinked. Finally, when drying the hybrid hydrogels at $60^{\circ} \mathrm{C}$, the liquids are evaporated at a faster rate than when they are dried at room temperature. Temperature may be involved in the chemical kinetics of hydrolysis-condensation reaction. Most of the organic byproducts may be expelled from the siloxane network, helping the hydrogels to densify their structure. FT-IR and Raman spectroscopies were needed to understand some of the chemical characteristics of the designed hybrid hydrogels: 1) HA-APTES grafting (chemical modification of HA molecules); 2) chemical crosslinking of HA with a siloxane inorganic network; 3) chemical incorporation of PDMS into the $\mathrm{SiO}_{2}$ network by having nanodomains rich in $\mathrm{SiO}_{2}$ and PDMS.

Nuclear Magnetic Resonance spectroscopy will confirm the chemical crosslinking of hyaluronate with a siloxane inorganic network. According to literature data (Crescenzi et al., 2002, 2003), the hyaluronate and APTES molecules have several types of carbons, which are 
A)

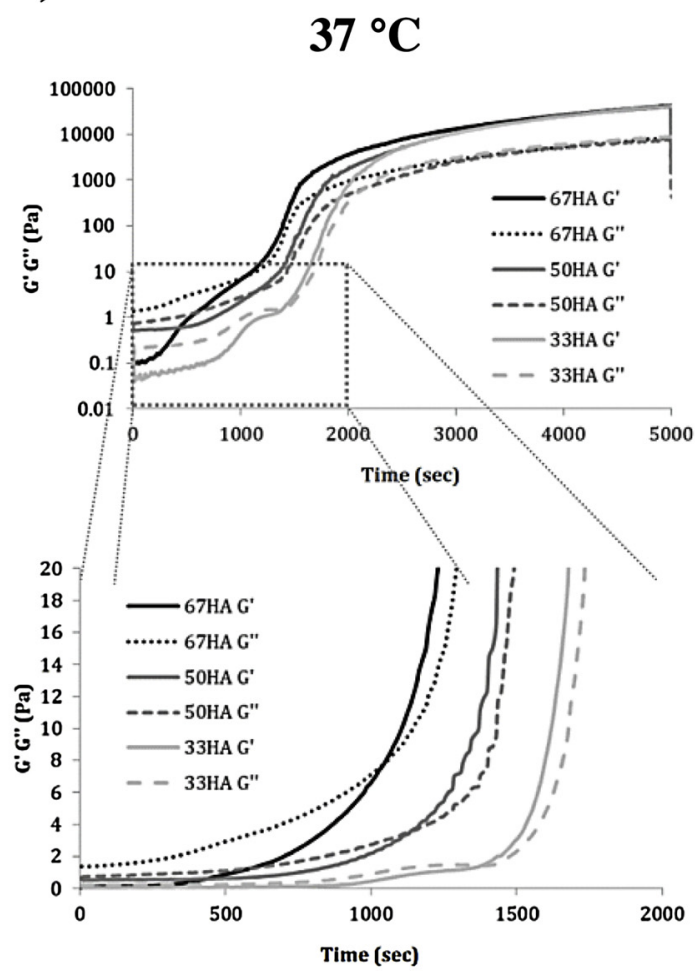

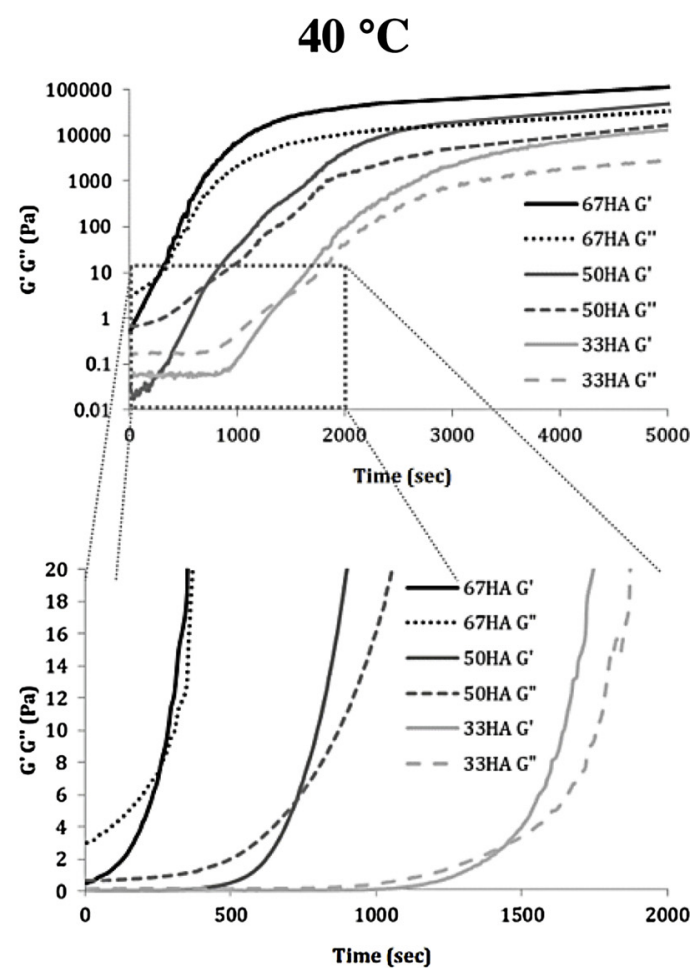

B)

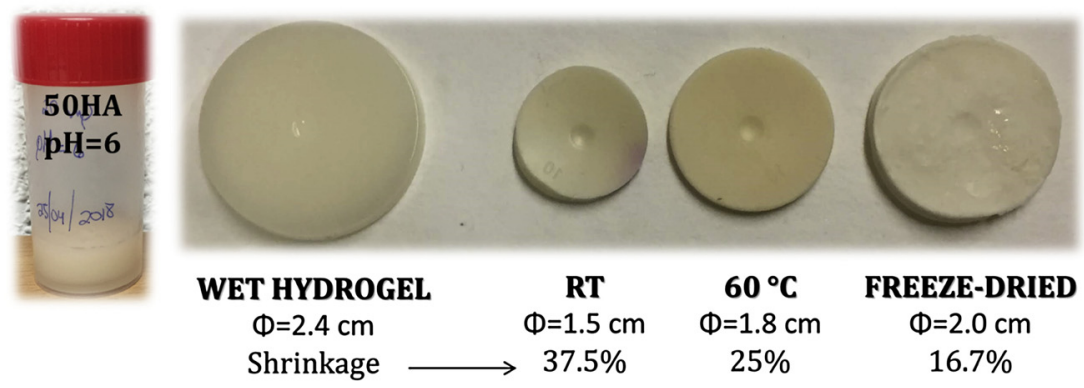

Fig. 3. A) Analysis of sol-gel transition time of HA-based hybrid hydrogels by dynamic time sweep at $37^{\circ} \mathrm{C}$ and $40^{\circ} \mathrm{C}$. B) Physical appearance of HA-based hybrid hydrogels before and after drying processes.

assigned in Fig. $5 .{ }^{13} \mathrm{C}$ MAS NMR spectra of the HA-based hybrid hydrogels can prove the coupling of APTES (primary amine) with HA molecules yielding amide bonds. ${ }^{13} \mathrm{C}$ MAS NMR is a semi-quantitative technique (Crescenzi et al., 2002). The following resonance peaks confirm the amidation of HA with APTES: 1) resonance at $36 \mathrm{ppm}$ (Ashu-Arrah \& Glennon, 2017; Ullah et al., 2018) is attributed to the carbon 6B from HA directly attached to the nitrogen atom of APTES molecules, resulting in the formation of an amide bond $(\mathrm{O}=\mathrm{C}-\mathrm{NH})$; 2) resonance at $53 \mathrm{ppm}$ (Peixoto, Fernandes, Pereira, Pires, \& Freire, 2016) is assigned to carbon $\mathrm{C} 3\left(\mathrm{CH}_{2}-\mathrm{NH}\right)$ bearing the grafting of hyaluronan molecules $\left(\mathrm{CH}_{2}-\mathrm{NH}-\mathrm{HA}\right)$. However, the presence of the peak at $43.5 \mathrm{ppm}$, assigned to carbon $\mathrm{C} 3\left(\mathrm{CH}_{2}-\mathrm{NH}_{2}\right)$, indicates that not all of the APTES molecules were attached to hyaluronan; 3) resonance at $160 \mathrm{ppm}$ (Ullah et al., 2018), attributed to amides, may also confirm HA-APTES coupling. Resonance peak at $46 \mathrm{ppm}$ attributed to $-\mathrm{C}-\mathrm{OH}$ can be due to self-condensation between the $-\mathrm{COO}^{-} \mathrm{Na}^{+}$ and $-\mathrm{OH}$ groups in hyaluronic-based materials (Hu et al., 2011). Moreover, the presence of resonances at $60 \mathrm{ppm}$ and $17 \mathrm{ppm}$ due to carbons C4 and C5 in APTES molecules and resonance at $48 \mathrm{ppm}$ (Ullah et al., 2018) due to $-\mathrm{CH}_{2}-$ from APTES suggest that hydrolysis reactions may have not occur in all ethoxy groups within the APTES molecules. Finally, the chemical incorporation of PDMS into the $\mathrm{SiO}_{2}$ network can be observed in the resonances peaks arising from the chain end $\mathrm{M}$ siloxane units at $1.8 \mathrm{ppm}$ and the $\mathrm{D}$ siloxane units at $0.6 \mathrm{ppm}$ (Hill, Preston, \& Whittaker, 2002). ${ }^{13} \mathrm{C}$ MAS NMR spectra of hybrid hydrogels dried at room temperature present two resonances, one at $36 \mathrm{ppm}$ and the other at $38 \mathrm{ppm}$, both attributed to (carbon $6 \mathrm{~B}$ from HA) $-\mathrm{C}-\mathrm{NH}$ and $-\mathrm{C}-\mathrm{NH}_{2}$ bonds, respectively. Resonance at $36 \mathrm{ppm}$ confirms HA-APTES coupling, as mentioned before. Resonance at $38 \mathrm{ppm}$ (Ullah et al., 2018) may be attributed to amine reactive intermediates resulting from reactions between EDC and NHS with HA. These intermediates may have not reacted with the primary amine (APTES), triggering their entrapment within the siloxane network as the structure got densified when drying at room temperature. However, ${ }^{13} \mathrm{C}$ MAS NMR spectra of freeze-dried hybrid hydrogels and hybrid hydrogels dried at $60^{\circ} \mathrm{C}$ do not present a sharp resonance at $38 \mathrm{ppm}$ since the amine reactive intermediates may have been expelled from the siloxane network through drying processes.

Structural changes caused by the hydrolytic-polycondensation reactions in HA-based hybrid hydrogels can be detected by ${ }^{29}$ Si MAS NMR 
A)

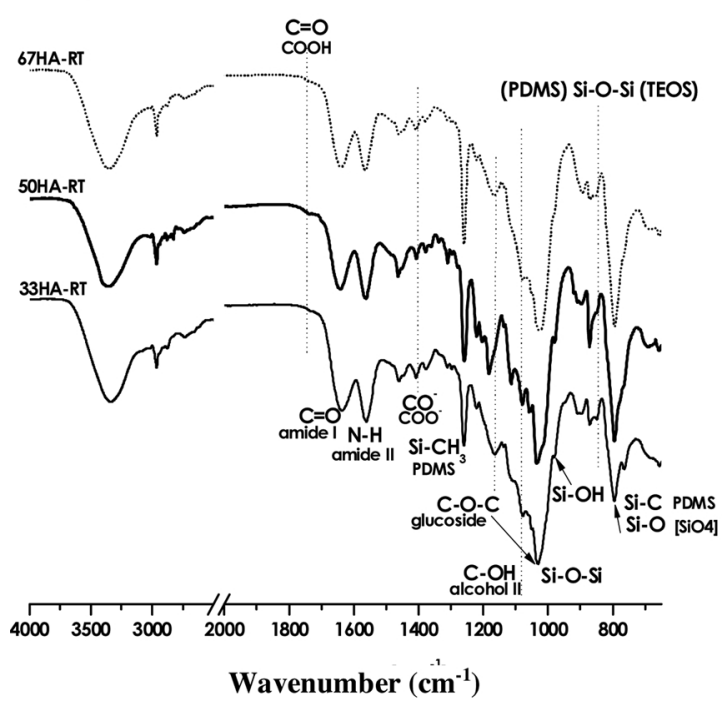

Room temperature-dried HA-based hybrid hydrogels

B)

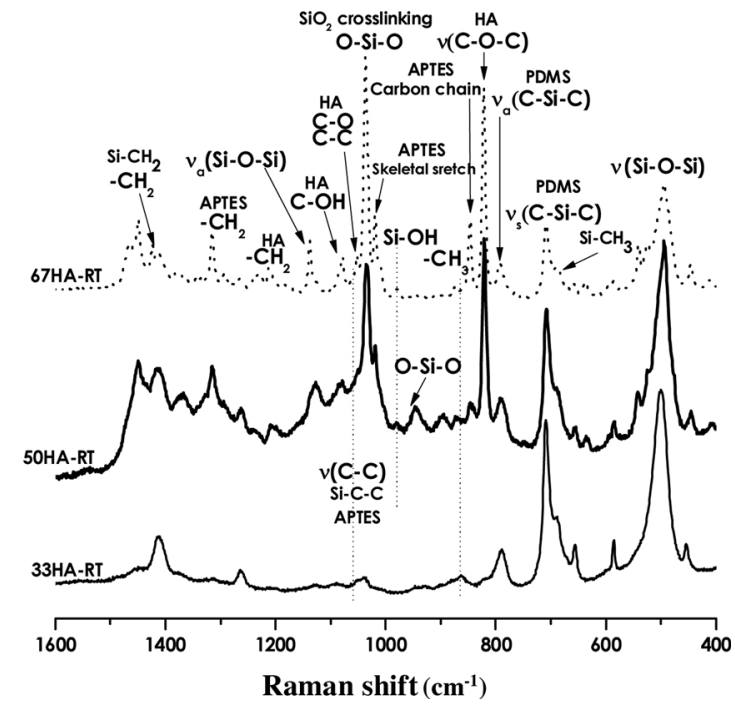

Fig. 4. A) FT-IR and B) Raman spectra of selected HA-based hybrid hydrogels.

spectroscopy. The formation of monodentate, bidentate or polymeric $\mathrm{Si}$ species in the studied HA hybrid hydrogels can be observed in the ${ }^{29} \mathrm{Si}$ MAS NMR spectra shown in Fig. 6.

The ${ }^{29} \mathrm{Si}$ MAS NMR spectra of HA-based hybrid hydrogels show several $\mathrm{Si}$ resonances, proving the formation of a siloxane organic-inorganic network crosslinking the hyaluronic acid. The hybrid hydrogels spectra show signals between $-40 \mathrm{ppm}$ and-80 ppm belonging to the grafted organic groups (HA-APTES) (Zhao et al., 2017). Specifically, these signals, $\boldsymbol{T}$ units, are attributed to trifunctional species (APTES) covalently bonded to organosilanes precursors (TEOS-PDMS) through hydrolysis-polycondensation reactions between one, two or three ethoxy groups from APTES and the - $\mathrm{OH}$ groups from TEOS and PDMS.

Trifunctional species, $\mathbf{T}$ units $\left(\mathrm{SiO}_{3}-\mathrm{CH}_{2} \mathrm{CH}_{2} \mathrm{CH}_{2} \mathrm{NH}_{2}\right)$, are labeled as follows: 1) monodendate species, $T_{1}$ from $-46 \mathrm{ppm}$ to- $50 \mathrm{ppm}$, are assigned to a) hydrolyzed aminopropylsilane, $\boldsymbol{S i}(-\mathrm{OR} / \mathrm{H})_{3}-\mathrm{CH}_{2} \mathrm{CH}_{2} \mathrm{CH}_{2} \mathrm{NH}_{2}$ or b) aminopropylsilane silicon attached via one siloxane bond, $(-\mathrm{O}-)_{1} \mathrm{Si}-\mathrm{CH}_{2} \mathrm{CH}_{2} \mathrm{CH}_{2} \mathrm{NH}_{2}$ and/or $\mathrm{Si}(-\mathrm{OSi})(-\mathrm{OR} / \mathrm{H})_{2}-\mathrm{CH}_{2} \mathrm{CH}_{2} \mathrm{CH}_{2} \mathrm{NH}_{2}$. Note: the chemical shift at $-46 \mathrm{ppm}$, corresponding to chemical shift of silicon in liquid (APTES) may indicate free silane molecules physically adsorbed on the hybrid hydrogels surface; 2) bidendate species, $T_{2}$ at $-56 \mathrm{ppm}$, are assigned to aminopropylsilane silicon attached via two siloxane bonds, $(-\mathrm{O}-)_{2} \mathrm{Si}-\mathrm{CH}_{2} \mathrm{CH}_{2} \mathrm{CH}_{2} \mathrm{NH}_{2}$ and/or $\mathrm{Si}(-\mathrm{OSi})_{2}(-\mathrm{OR} / \mathrm{H})-\mathrm{CH}_{2}$ $\mathrm{CH}_{2} \mathrm{CH}_{2} \mathrm{NH}_{2}$; and 3) crosslinked species, $\mathrm{T}_{3}$ at $-67 \mathrm{ppm}$, associated to aminopropylsilane silicon attached via three siloxane bonds, $(-\mathrm{O}-)_{3} \mathrm{Si}-\mathrm{CH}_{2} \mathrm{CH}_{2} \mathrm{CH}_{2} \mathrm{NH}_{2}, \quad \mathrm{~T}_{3}, \mathrm{~T}_{m}=\mathrm{RSi}(\mathrm{OSi})_{m}\left(\mathrm{OR}^{\prime}\right)_{3-m}, m \leq 3$, $R, R^{\prime}=H$ or hydrocarbon chain (Albert, Pfl, eiderer, Bayer, \& Schnabel, 1991; Duan, Jana, Lama, \& Espe, 2015; Luan, Fournier, Wooten, \& Miser, 2005; Peixoto et al., 2016).

Other chemical shifts may appear in the ${ }^{29} \mathrm{Si}$ MAS NMR spectra of HA-based hybrid hydrogels between -80 to $-120 \mathrm{ppm}$, assigned to tetrafunctional $\mathbf{Q}$ structural units $\left(\mathrm{SiO}_{4}\right)$. Signals of silanol $(\mathrm{Si}-\mathrm{OH})$ groups associated with vicinal or free silanols and siloxanes can appear: 1) $Q_{1}$ at $-83 \mathrm{ppm}$ is assigned to $\boldsymbol{S i}(\mathrm{OSi})_{1}(\mathrm{OH})_{3}$ structural units; 2) $Q_{2}$ at $-92 \mathrm{ppm}$ is assigned to $\mathbf{S i}(\mathrm{OSi})_{2}(\mathrm{OH})_{2}$ structural units.; 3) $Q_{3}$ at $-101 \mathrm{ppm}$ is assigned to $\mathbf{S i}(\mathrm{OSi})_{3} \mathrm{OH}$ structural units; 4) $Q_{4}$ at $-110 \mathrm{ppm}$ is assigned to $\mathbf{S i}(\mathrm{OSi})_{4}$ structural units, $\left(Q_{4}, Q_{n}=S i(O S i)_{n}(O H)_{4-n}, n \leq 4\right)$ (Albert et al., 1991; Almeida et al., 2016). In the ${ }^{29} \mathrm{Si}$ MAS NMR spectra of HA-based hybrid hydrogels the $Q_{4}$ structural units represent interlinked $\mathrm{SiO}_{4}$ tetrahedrons in the interior of the hybrid structure of hydrogels, while $Q_{3}, Q_{2}$ structural units, associated to silanol $(\mathrm{Si}-\mathrm{OH})$ groups, are located on the hydrogels surface. The chemical shifts referred to $T_{2}$ and $T_{3}$ indicate the formation of new siloxane linkages $(\mathrm{Si}-\mathrm{O}-\mathrm{Si}$ ) of APTES silicon with surface silicon $Q_{3}, Q_{2}$ structural units from TEOS. The relative high intensity of $T_{3}$ chemical shift indicates that the incorporated aminopropyl groups are closely packed into the internal surface of HA-hybrid hydrogels, suggesting that surface silanol $(\mathrm{Si}-\mathrm{OH})$ groups, associated to $\mathrm{Q}_{2}$ and $Q_{3}$ structural units in hybrid hydrogels are attached to aminopropylsilane (APTES) molecules via siloxane bonds (Luan et al., 2005). Although $T_{2}$ signal has low intensity in ${ }^{29} \mathrm{Si}$ MAS NMR spectra, it implies different grafting degrees for different hybrid-organosilanes hydrogels composition (Peixoto et al., 2016). The relative absence of chemical shifts between -46 and $-50 \mathrm{ppm}$ could be attributed to $T_{1}$ prompts that APTES has reacted forming the siloxane structure in the aerogels and xerogels (Duan et al., 2015).

Two distinct groups of silicon $(\mathrm{Si})$ structural units coming from PDMS are observed; one type at the chain ending ( $M$ units) and the other type being characteristic of the silicon atoms within the chain (D units). These silicon units are labeled according to the standard shorthand nomenclature for siloxane polymers. The ${ }^{29} \mathrm{Si}$ MAS NMR spectra of hybrid hydrogels show two resonance peaks due to the incorporation of PDMS within the $\mathrm{SiO}_{2}$ structure: 1) M siloxane units at a maximum of $\sim 7$ ppm due to ending PDMS chains; 2) $D$ siloxane units within the silicon chain at a maximum of $\sim 20 \mathrm{ppm}$ (Hill et al., 2002). Furthermore, in the ${ }^{29} \mathrm{Si}$ MAS NMR spectra of HA-based hybrid hydrogels show chemical shifts between -4 to $-23 \mathrm{ppm}$, which are assigned to difunctional dimethylsiloxane $\mathbf{D}$ structural units $\left(\left(\mathrm{CH}_{3}\right)_{2} \cdot \mathrm{SiO}_{2}\right)$ (Albert et al., 1991; Almeida et al., 2016; Meléndez-Zamudio et al., 2017). According to the different composition and drying process in HA-based hybrid hydrogels, D species can vary: 1) monodendate species, $D_{1}$ and $D_{2}$ at -4 ppm and-7 ppm, respectively; 2) bidentate species, $D_{3}$ at $-10 \mathrm{ppm} ; 3$ ) crosslinked species, $D_{4}$ between $-14 \mathrm{ppm}$ to- $23 \mathrm{ppm}$, which are described as $D_{A}$ near $-16 \mathrm{ppm}$; $D_{B}$ near $-19 \mathrm{ppm}$ and $D_{C}$ near $-21 \mathrm{ppm}$. Some authors (Almeida et al., 2014; Sánchez-Téllez et al., 2015) have assigned the chemical shift $D_{A}$ between $-15.5 \mathrm{ppm}$ and $-17.5 \mathrm{ppm}$ to D units crosslinked to oxide-based structures ( $D-Q$ bonds) in PDMS$\mathrm{SiO}_{2}$ and PDMS- $\mathrm{SiO}_{2}-\mathrm{CaO}$ systems, confirming that PDMS is chemically bonded to $\mathrm{SiO}_{2}$ inorganic network, both modifying the organic structure of the HA-based hydrogels, designed in the present work. Other authors (Almeida et al., 2014; Peña-Alonso et al., 2005) assigned the chemical shifts $D_{B}$ and $D_{c}$ either to cyclic PDMS molecules in four- 

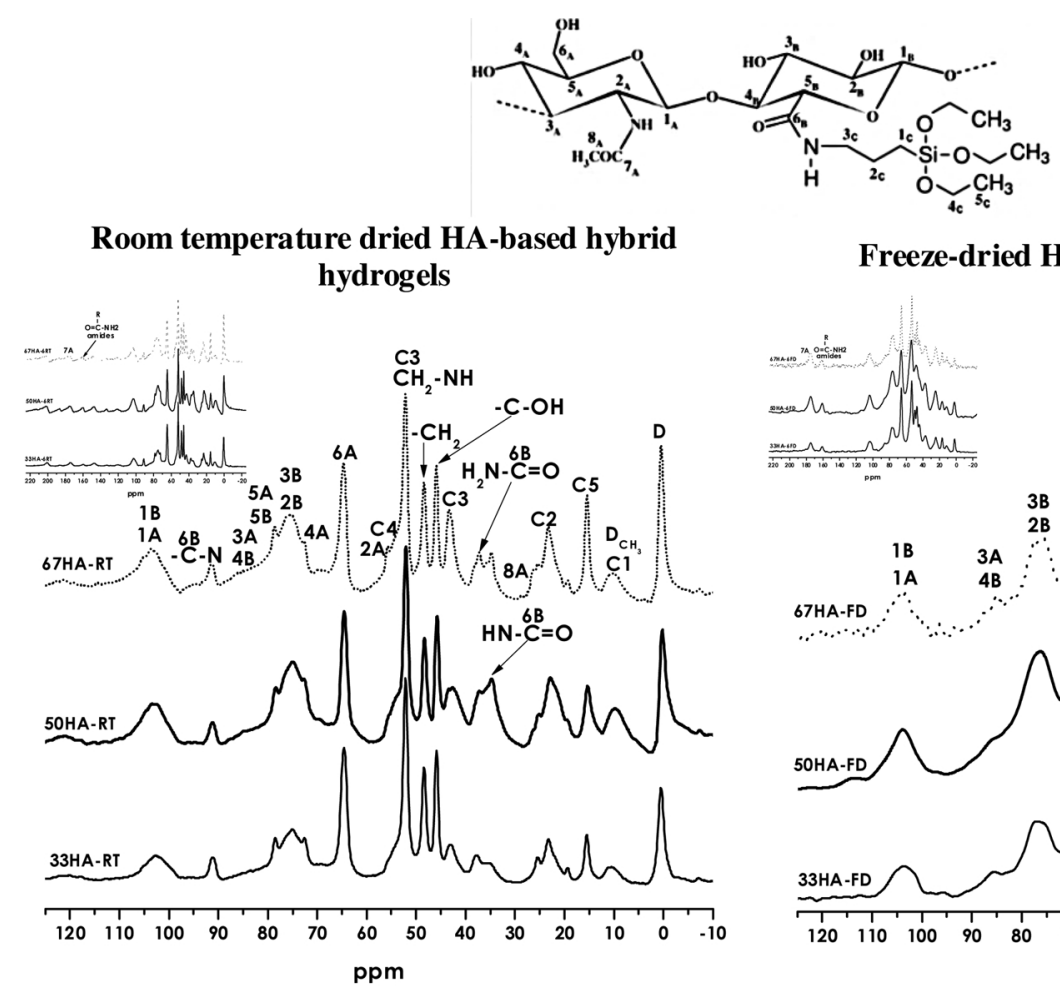

\section{Freeze-dried HA-based hybrid hydrogels}

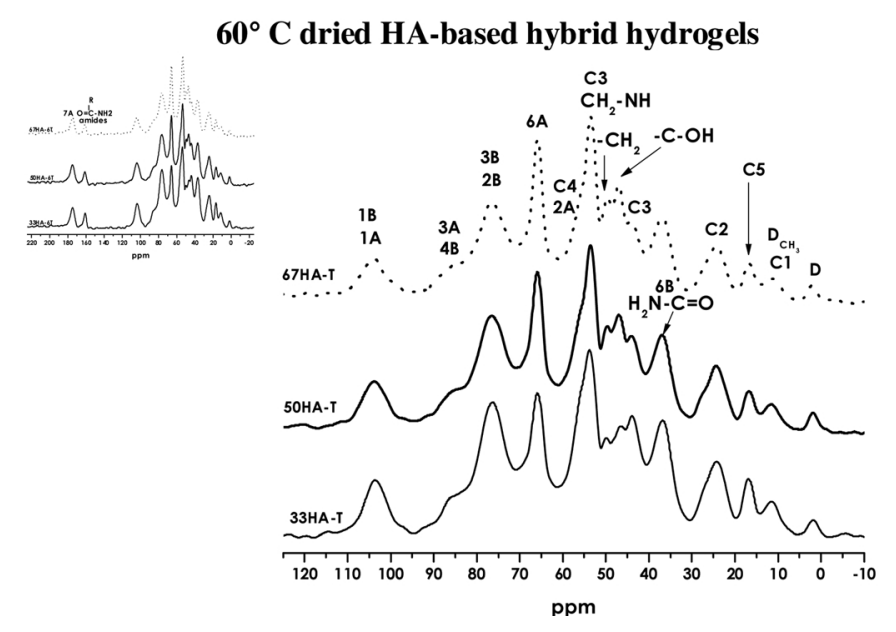

Fig. 5. ${ }^{13} \mathrm{C}$ MAS NMR spectra of HA-based hybrid hydrogels.

member rings or to $\mathrm{D}$ units located in different positions inside the PDMS chain, being in a less constrained environment and near to crosslinking points, like $D_{2}$ at a $D_{2}-D-Q$ structure.

From the above description, it can be observed that a higher HA concentration within the system decreases the chemical crosslinking of D units with $\mathrm{SiO}_{2}$ structures; which can be due to the great volume of the biopolymer HA chains and their electrostatic forces, hindering $D-Q$ hybrid bonds, but triggering the formation of $Q_{4}$ and $Q_{3}$ silicon domains and $D_{3}$ and $D_{2}$ PDMS domains. These observations may suggest that the HA-based hybrid hydrogels have nanodomains rich in silica, rich in silicone PDMS $\left(\left(\mathrm{CH}_{3}\right)_{2}-\mathrm{SiO}_{2}\right)$ and rich in HA. However, it is also probable that high molecular polymeric HA chains coated the siloxane network during room temperature drying process, inhibiting the crosslinking of PDMS domains with the $\mathrm{SiO}_{2}$ structure, therefore promoting an increase of $Q_{4}$ structures (Almeida et al., 2014). However, when decreasing HA concentration (33HA $<50 \mathrm{HA}<67 \mathrm{HA}$ ), less solid particles are dispersed into the hybrid sol-gel systems and PDMS modification leads to the formation of highly hybrid $D-Q$ crosslinked polymeric structures. This is observed in the chemical shift $D_{A}$ between $-15.5 \mathrm{ppm}$ and $-17.4 \mathrm{ppm}$; whereas increasing the dispersed solid particles into the system, monodentate and bidentate species are formed (Albert et al., 1991). ${ }^{29}$ Si MAS NMR spectra of HA-based hybrid hydrogels dried at room temperature present chemical shifts related to monodendate $M, D, T$ and $Q$ structural units trapped within the densified siloxane structure. When drying the hybrid hydrogels through freeze-drying process, the monodendate structural units are expelled from the crosslinked structure through supercritical conditions and polycondensation reactions are interrupted, causing the disappearance of resonance peaks assigned to monodendate units and a decrease in intensity of resonance peaks due to chemical shifts assigned to highly crosslinked $Q_{3}$ and $Q_{4}$ structural units. However, when drying HA-based hybrid hydrogels at $60^{\circ} \mathrm{C}$, resonance peaks attributed to $Q_{3}$ and $Q_{4}$ structural units show really low intensities, suggesting that temperature helps the polycondensation of monodendate $M, D, T$ structural units, enhancing the formation of hybrid $D-Q$ bonds. Finally, ${ }^{29} \mathrm{Si}$ MAS NMR spectra of freeze-dried hybrid hydrogels show a decrease in 
Freeze-dried HA-based hybrid hydrogels

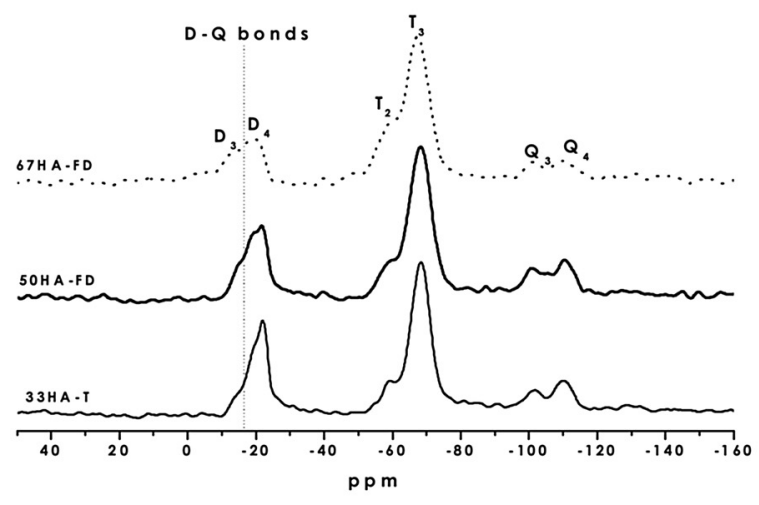

Room temperature dried HA-based hybrid hydrogels

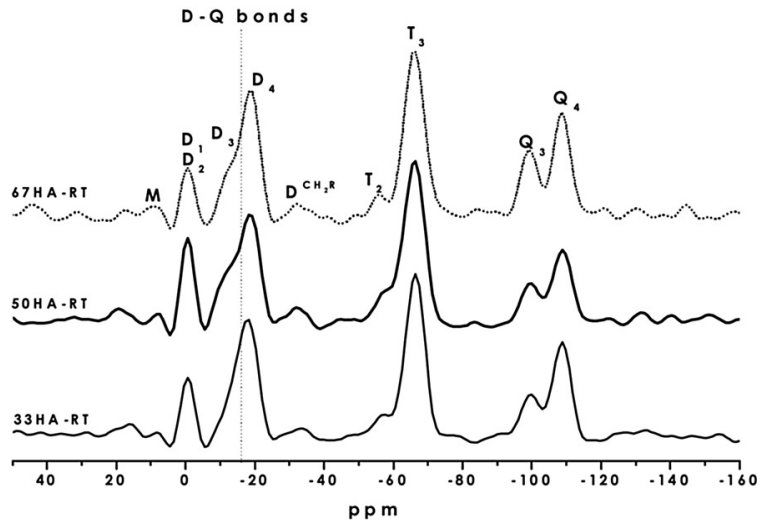

$60^{\circ} \mathrm{C}$ dried HA-based hybrid hydrogels

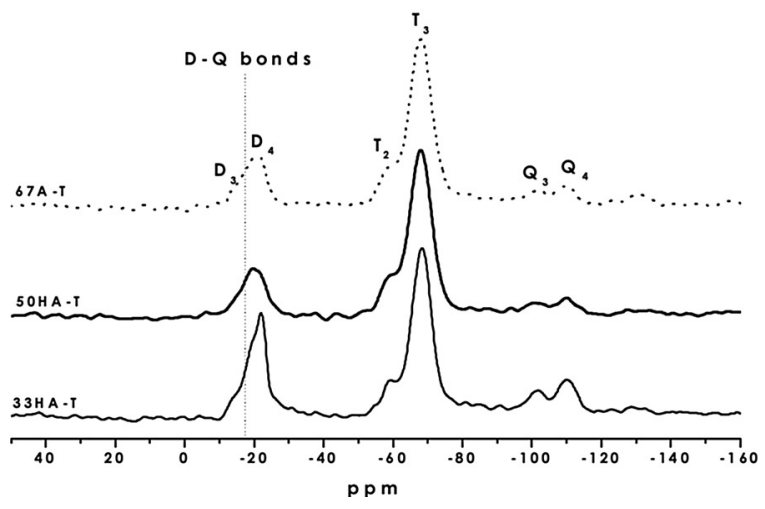

\section{Chemical}

shift

(ppm)

Assigned structure<smiles>CO[Si](C)(C)C</smiles><smiles>CC[Si](C)(O)OC</smiles>

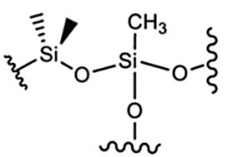<smiles>C[Si](C)(C)O[Te]</smiles><smiles>CCC[Si](C)(O[SiH3])O[Si](C)(C)C</smiles><smiles>C[13CH2]O[Si](C)(O)O[SiH3]</smiles>

$T_{2}:-$ 56

$T_{3}:-$ 67

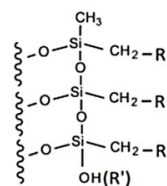<smiles>CCO[Si](OC)(OC)OCC</smiles>

$-108$

Fig. 6. ${ }^{29} \mathrm{Si}$ MAS NMR spectra of HA-based hybrid hydrogels.

intensity of the chemical shift related to $Q_{4}$ structural units in comparison to hybrid hydrogels dried at room temperature. This can be attributed to an increase of $Q_{3}$ structural units resulted from the high surface area exposed in the hybrid hydrogel caused by the type of drying process, which promoted greater porosity and larger number of surface hydroxyl groups. These hydroxyl groups $(-\mathrm{OH})$ were unable to polycondense into a highly crosslinked $\mathrm{SiO}_{2}$ structure (more $Q_{4}$ structural units) as the hybrid hydrogels were getting freeze (Duan et al., 2015).

\subsection{Morphological characterization of the HA-based hybrid hydrogels}

The designed HA-based hybrid hydrogels have micrometric organic- inorganic interpenetrating networks. Fig. 7 shows SEM images, at different magnifications, of 50HA-based hybrid hydrogels morphology. Pore diameters were obtained by measuring them directly on SEM images. Non statistic study was made. Similar morphologies are observed in all the hybrid materials. These materials exhibit some surface irregularities (Tamayo \& Rubio, 2010) and different pore shapes and sizes, showing pore diameters between $5 \leq \phi \leq 30 \mu \mathrm{m}$. Synthesis conditions, aging and drying process have strong influence on hybrid hydrogel textural properties. Pore size is closely related to the reagent addition rate and the type of solvent used in the sol-gel process. Porous structure is closely related to aging and drying conditions, resulting in the appearance of different kinds of pores (Tamayo \& Rubio, 2010).

From SEM images, it is observed that freeze-drying process in 50HA- 


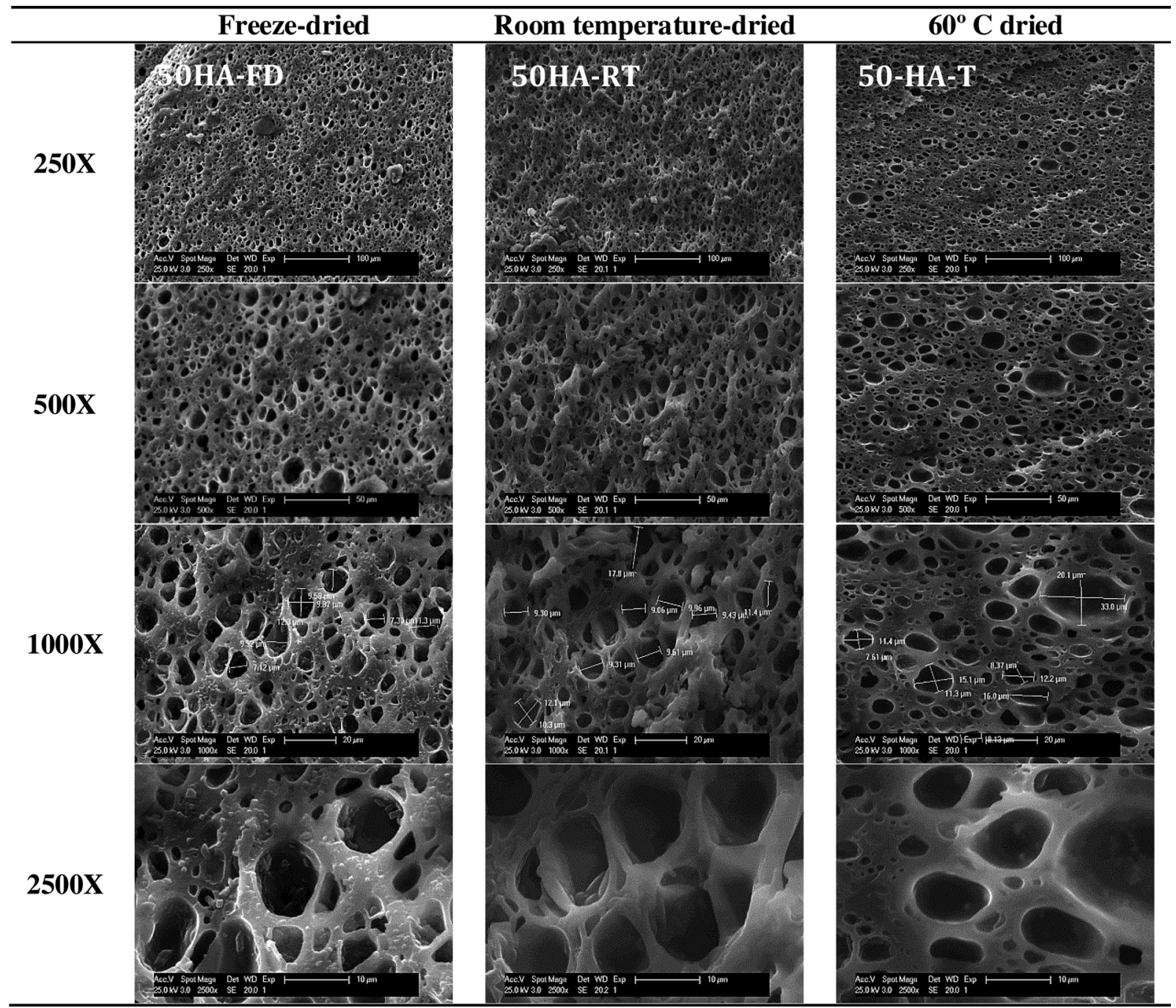

Fig. 7. Morphology, pore shape and size in 50HA-based hybrid hydrogels.

FD hybrid hydrogels produced highly porous morphologies with abundant small irregular pores with mean pore diameters of $\phi<10 \mu \mathrm{m}$. Irregularities in pore shape and size are due to the formation of water crystals when freezing the hybrid hydrogels at $-20^{\circ} \mathrm{C}$. However, since ethanol (byproduct of hydrolysis reactions) freezes at $-110^{\circ} \mathrm{C}$, it remains in liquid state within the hydrogel structure when water is freeze, leading to the formation of semi round porous when ethanol is expelled (in gas form) from the hybrid matrix. Room temperature drying process of 50HA-RT hybrid hydrogels produced materials with rougher surface morphologies in comparison with morphologies produced by freezedrying process, with round pores of $10 \leq \phi \leq 15 \mu \mathrm{m}$. This can be due to a slow but constant drying rate, which helps the hybrid structure to shrink slowly and densify by reducing number and size of pores. This type of drying process can make the hybrid hydrogel to shrink until its structure collapse due to capillary tension (Tamayo \& Rubio, 2010). $60{ }^{\circ} \mathrm{C}$ drying process produces morphologies with flat surfaces and big pores. Liquids (ethanol and water) entrapped within the surface layers are evaporated rapidly, producing pores with $20 \leq \phi \leq 30 \mu \mathrm{m}$ in 50HA$\mathrm{T}$ hybrid hydrogels. Liquids trapped within inner matrix layers delay to reach evaporation temperature, decreasing their evaporation rate and producing pores with smaller diameters, between $5 \leq \phi \leq 15 \mu \mathrm{m}$.

As it can be seen, drying process affects directly the hybrid hydrogels porous morphology. Freeze-drying process is the one that produces the smallest pores. In $60{ }^{\circ} \mathrm{C}$ drying process, the biggest and most separated pores are observed, as well as a wider pore size distribution (5-30 $\mu \mathrm{m})$ than that observed for freeze-drying (not greater than $10 \mu \mathrm{m}$ ) and room temperature drying $(10 \leq \phi \leq 15 \mu \mathrm{m})$ processes.

\subsection{Thermal characterization of the HA-based hybrid hydrogels}

HA-based hybrid hydrogels were thermally characterized to identify temperatures at which thermal decomposition occurs. Polymer fraction (HA and PDMS) in HA-based hybrid hydrogels was studied by thermal decomposition under air atmosphere. Thermogravimetric analysis (TGA) of HA-based hybrid hydrogels is shown in Fig. 8. HA-based hybrid hydrogel (67HA, 50HA and $33 \mathrm{HA}$ ) dried through different drying processes (freeze-drying, room temperature drying or $60^{\circ} \mathrm{C}$ drying) are compared.

TGA analysis in HA-based hybrid hydrogels has several stages of weight loss. The first thermal stage occurs between $40^{\circ} \mathrm{C}$ and $150{ }^{\circ} \mathrm{C}$, being attributed to adsorbed water loss and residual water and ethanol loss by evaporation, both are byproducts of hydrolysis-polycondensation reactions (Huerta-Angeles et al., 2016; Lewandowska, Sionkowska, Grabska, \& Michalska, 2017). Room temperature-dried HA-based hybrids are the hydrogels with larger amount of water and ethanol entrapped within the structure, thus experiencing greater weight losses $\sim 5.5 \%$ at $\sim 116^{\circ} \mathrm{C}$ in comparison to freeze-dried hybrid hydrogels (weight losses $\sim 2.55 \%$ at $\sim 82^{\circ} \mathrm{C}$ ) and $60{ }^{\circ} \mathrm{C}$-dried hybrid hydrogels (weight losses $\sim 2.55 \%$ at $\sim 111^{\circ} \mathrm{C}$ ). The second thermal stage occurs between $200-380^{\circ} \mathrm{C}$. The main decomposition of pure hyaluronic 




Fig. 8. Thermogravimetric analysis (TGA) of HA-based hybrid hydrogels.

acid, attributed to the partial break of its molecular structure, takes place at a temperature range between $200{ }^{\circ} \mathrm{C}$ and $300{ }^{\circ} \mathrm{C}$ ( $T_{\text {onset }}$ at $214^{\circ} \mathrm{C}$ ) (Lewandowska, Sionkowska, Grabska, \& Kaczmarek, 2016). The designed HA-based hybrid hydrogels have an average weight loss of $\sim 21 \%$ at $\sim 215^{\circ} \mathrm{C}$ and the HA residues are further degraded at $\sim 312^{\circ} \mathrm{C}$, presenting weight losses between $30 \%$ and $60 \%$.
33HA-based hybrids dried at both, room temperature and $60^{\circ} \mathrm{C}$, reached almost a $60 \%$ of weight loss. This second stage, attributed to HA thermal degradation, involves the disintegration of intermolecular bonds and the partial breaking of high molecular HA polymeric chains into lower molecular HA polymeric chains. It is observed that derivative thermo-stability in hydrogels is clearly influenced by the hybrid hydrogels composition and drying process.

The earliest thermal degradation for the second stage was found for the hybrids with less HA concentration (33HA) as follows: 33HA-T hydrogel dried at $60^{\circ} \mathrm{C}\left(T_{\text {onset }}\right.$ at $208.49^{\circ} \mathrm{C}$, mas loss $\left.19.24 \%\right)$, then 33HART dried at room temperature ( $T_{\text {onset }}$ at $211.05^{\circ} \mathrm{C}$, mas loss $25.28 \%$ ) and finally by freeze-dried 33HA-FD ( $T_{\text {onset }}$ at $214.90^{\circ} \mathrm{C}$, mas loss $18.30 \%$ ). According to this information, drying the 33HA hybrid hydrogels at $60{ }^{\circ} \mathrm{C}$ might have cause a pre-degradation of HA, producing less thermostable materials. On the other hand, 50HA-FD hybrid hydrogel was the most thermostable hydrogel during the second stage (HA degradation), having $T_{\text {onset }}$ at $217.46^{\circ} \mathrm{C}$ and $357.13^{\circ} \mathrm{C}$ with weight losses of $28.87 \%$ and $38.97 \%$, respectively. This could be caused by a better efficiency in HA chemical modification (HA-APTES grafting) and to the possible hydrogen bonding interaction between molecules due to the presence of amino $\left(-\mathrm{NH}_{2}\right)$ and hydroxyl $(-\mathrm{OH})$ groups in APTES, TEOS and PDMS as well as $(-\mathrm{OH}),(\mathrm{COOH}),(\mathrm{C}=\mathrm{O})$ in hyaluronic acid (Lewandowska et al., 2016).

The increase of temperature at which HA thermal degradation occurs in the designed HA-based hybrid hydrogels $\left(T=214^{\circ} \mathrm{C}-219^{\circ} \mathrm{C}\right)$ may suggest that chemically modified HA chains (HA-APTES molecules) are thermally more stable than non-hibridized HA chains. The incorporation of APTES may have provided thermal stability to HA polymeric chains, since the incorporated aminopropyl groups are closely packed into the internal surface of HA-hybrid hydrogels, working as bridging points between HA polymeric chains and the siloxane structure, resulting in a siloxane structure coated by high molecular HA polymeric chains (Duan et al., 2015), as shown in Fig. 9. On the other hand, the HA-based hybrid hydrogels dried at room temperature and at $60{ }^{\circ} \mathrm{C}$ present lower temperatures $\left(T<214^{\circ} \mathrm{C}\right)$ at which HA thermal degradation occurs. This can be due to low molecular polymeric HA chains and chemically unmodified polymeric HA chains, which may be located between silica and PDMS domains, affecting the number and

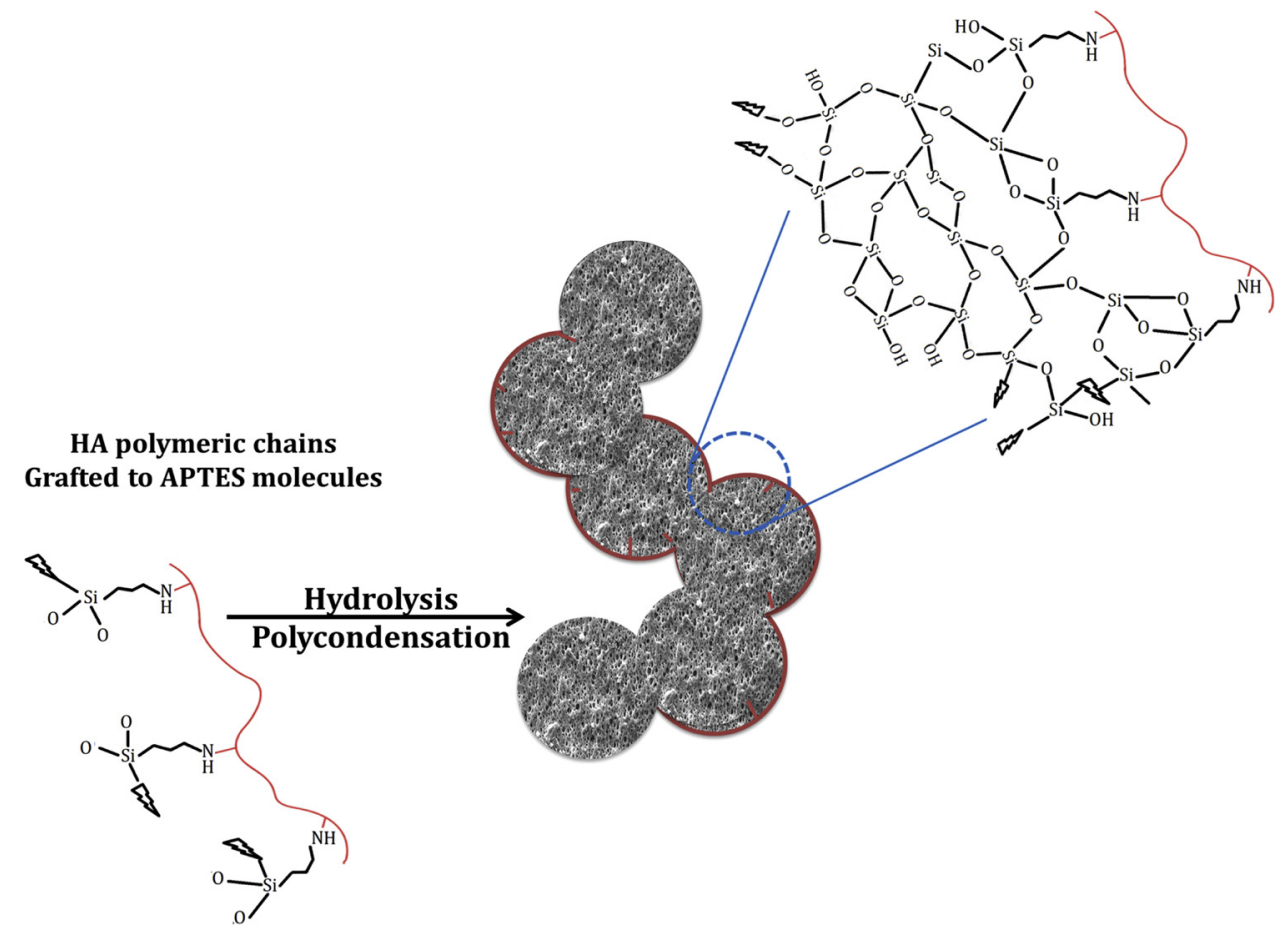

Fig. 9. Siloxane structure coated by high molecular HA polymeric chains, chemically bonded by aminosilane molecules to form HA-based hybrid hydrogels. 
nature of crosslinking between those domains, thus facilitating HA thermal degradation to start.

The third thermal stage, attributed to PDMS chain thermal degradation, takes place between $400^{\circ} \mathrm{C}$ and $600^{\circ} \mathrm{C}$. During thermal PDMS degradation, two simultaneous and competitive degradation mechanisms are produced: 1) molecular mechanism occurring through cyclic oligomers formation due to the redistribution of siloxane bonds, with the participation of $d$ orbitals of silicon ( $\mathrm{Si}$ ) atoms generating porosity; and 2) radical mechanism consisting on the direct oxidation of methyl groups via hydroperoxide formation, decomposing silicone into $\mathrm{CO}_{2}, \mathrm{H}_{2} \mathrm{O}$ and $\mathrm{H}_{2}$, causing mineralization of the material and further densification (Tamayo \& Rubio, 2010). According to Almeida et al. (2014), weight loss at $\sim 375^{\circ} \mathrm{C}$ is attributed to PDMS decomposition, forming cyclic oligomers (mainly hexamethylcyclotrisiloxane) through $\mathrm{Si}-\mathrm{O}$ bond scission, resulting in a chain folded cyclic conformation which is energetically more favorable. The second weight loss that arises above $\sim 400^{\circ} \mathrm{C}$ is related to the final decomposition of the cyclic oligomers.

According to the above data, HA-based hybrid hydrogels show better thermal stability since the initial PDMS degradation appears at higher temperature, between $400^{\circ} \mathrm{C}$ and $600^{\circ} \mathrm{C}$. The first derivative peak at $\sim 487^{\circ} \mathrm{C}$ corresponds to methyl oxidation, from $\mathrm{Si}-\mathrm{CH}_{3}$ bonds, which is assumed to be initiated by $\mathrm{O}_{2}$, by means of hemolytic cleavage mechanism to form silanol $(\mathrm{Si}-\mathrm{OH})$ groups, which would condense into siloxane bridges at higher temperatures. Additionally, this first peak may have also arisen due to the oxidation of aminopropyl groups from APTES molecules, being ungrafted during thermal degradation of HA. According to some authors (Almedia et al., 2014), when hybrid materials are heated above $300^{\circ} \mathrm{C}$, some $D$ units are oxidized to $T$ units and then to further $Q$ units. The second derivative peak at $\sim 550^{\circ} \mathrm{C}$ is related to the final decomposition of the cyclic PDMS oligomers. During these two degradation steps, the major degradation products are a mixture of oligomers with $\mathrm{CO}_{2}$ and water. According to Peña-Alonso et al. (2005), the chemical incorporation of APTES into a siloxane structure produces an increase in the temperature at which both derivative peaks of PDMS thermal degradation appear, boosting thermal stability in HA-based hybrid hydrogels. Moreover, the increasing temperature at which derivative peaks appear may indicate that most methyl and aminopropyl groups, from PDMS and APTES, are located over the whole hydrogel volume, being difficult to remove, suggesting an homogeneous incorporation of PDMS and APTES into the materials network, though siloxane nano domains are present (Peña-Alonso et al., 2005; Tamayo \& Rubio, 2010). Chain conformation of PDMS into the hybrid hydrogels directs the kinetic of its thermal decomposition reaction. As oxidative degradation of PDMS begins with the oxygen attacking dimethyl groups $\left(\mathrm{Si}-\left(\mathrm{CH}_{3}\right)_{2}\right)$, the more accessible is the organic group, the activation energy to accomplish depolymerization reaction is lower (Tamayo \& Rubio, 2010). Thus, the greater the number and size of pores is in the materials (greater exposed surface area), as in freeze-dried HA-based hybrid hydrogels, the easier is for the oxygen to attack methyl groups $\left(\mathrm{Si}-\left(\mathrm{CH}_{3}\right)_{2}\right)$, decreasing degradation temperature of PDMS thermal decomposition. Consequently, freezedried HA-based hybrid hydrogels present PDMS thermal degradation at lower temperatures $\left(T_{\text {onset }} \sim 450-482^{\circ} \mathrm{C}\right)$ than in the HA-based hybrid hydrogels dried at room temperature $\left(T_{\text {onset }} \sim 486-500^{\circ} \mathrm{C}\right)$ and HAbased hybrid hydrogels dried at $60^{\circ} \mathrm{C}\left(T_{\text {onset }} \sim 487-505^{\circ} \mathrm{C}\right)$.

A fourth final significant stage of weight loss appears above $600{ }^{\circ} \mathrm{C}$. At this temperature, hybrid materials completely oxidize their organic components (HA, methyl groups in PDMS and aminopropyl groups in APTES), leaving as residues only amorphous silica. When all the organic components are degraded, inorganic polycondensation reactions take place, resulting in the formation of $Q_{4}$ structural units, representing a $\left[\mathrm{SiO}_{4}\right]$ tetrahedron-network. Thus, drying and oxidative conditions play an important role in thermo-oxidative resistance, changing thermal history of hybrid hydrogels (Huerta-Angeles et al., 2016).

\section{Conclusions}

3D hybrid hydrogels, using polysaccharides such as sodium hyaluronate (HA) modified with aminosilane molecules and inorganically crosslinked by a siloxane organic-inorganic structure, were successfully developed. HA-based siloxane organic-inorganic hybrid hydrogels were characterized to study their physical, chemical and rheological properties. The polysaccharide chains were chemically modified and hybridized via amidation of the carboxylic groups with inorganic modifier molecules. The polysaccharide chains were crosslinked by a three dimensional siloxane organic-inorganic matrix via sol-gel method. Inorganic crosslinking was used to give strength to HA matrix by decreasing its natural hydrophilicity, improving rheological properties and increasing thermal degradation temperatures. Synthesis conditions such as starting polysaccharide concentration solution and temperature determined gelling (sol-gel transition) times and efficiency in the polysaccharide chemical modification and further hydrolysis-condensation reactions to build up the siloxane organic-inorganic matrix. Drying process affects thermal degradation of hybrid hydrogels. Exploring the rarely type of 3D inorganic chemical crosslinking of polysaccharide polymer matrixes to form Class II hybrid organic-inorganic polysaccharide-based hydrogels can guide the formation of novel materials with outstanding thermal and rheological properties, varying from soft mineralized hydrogels to hard compact xerogels.

\section{Funding}

This work was fund by EHME-CSIC 2015 program (MIIE-200011), Spain-Mexico; SIP/IPN project (20196660), Mexico; and AEI-MINECO (DPI 2017-90147-R), Spain.

\section{Declaration of Competing Interest}

The authors declare that there are no conflicts of interest.

\section{Acknowledgements}

LTJ received fellowships from COFAA, EDI and SNI. DAST acknowledges CONACYT, EHME-CSIC and PIFI for the scholarships given. LMRL acknowledges the funding from MINECO-AEI.

\section{Appendix A. Supplementary data}

Supplementary material related to this article can be found, in the online version, at doi:https://doi.org/10.1016/j.carbpol.2019.115590.

\section{References}

Albert, K., Pfleiderer, B., Bayer, E., \& Schnabel, R. (1991). Characterization of chemically modified glass surfaces by $13 \mathrm{C}$ and $29 \mathrm{Si}$ CP/MAS NMR Spectroscopy. Journal of Colloid and Interfaces Science, 142, 35-40.

Alkrad, J. A., Mrestani, Y., Stroehl, D., Wartewig, S., \& Neubert, R. (2003). Characterization of enzymatically digested hyaluronic acid using NMR, Raman, IR, and UV-Vis spectroscopies. Journal of Pharmaceutical and Biomedical Analysis, 31, 545-550.

Almeida, J. C., Castro, A. G. B., Lancastre, J. J. H., Miranda Salvado, I. M., Margaça, F. M. A., Fernandes, M. H. V., et al. (2014). Structural characterization of PDMS-TEOSCaO-TiO2 hybrid materials obtained by solegel. Materials Chemistry and Physics, 143, $557-563$.

Almeida, J. C., Wacha, A., Gomes, P. S., Alves, L. C., Vaz Fernandes, M. H., Miranda Salvado, I. M., et al. (2016). A biocompatible hybrid material with simultaneous calcium and strontium release capability for bone tissue repair. Materials Science and Engineering C, 62, 429-438.

Ashu-Arrah, B. A., \& Glennon, J. D. (2017). Supercritical carbon dioxide versus toluene as reaction media in silica functionalisation: Synthesis and characterisation of bonded aminopropyl silica intermediate. Journal of Chromatography A, 1501, 18-25.

Cai, D., Neyer, A., Kuckuk, R., \& Heise, H. M. (2010). Raman, mid-infrared, near-infrared and ultraviolet-visible spectroscopy of PDMS silicone rubber for characterization of polymer optical waveguide materials. Journal of Molecular Structure, 976, 274-281.

Chiu, Y.-C., Ma, C.-C. M., Lui, F.-Y., Chiang, C.-L., Riang, L., \& Yang, J.-C. (2008). Effect of $\mathrm{P} / \mathrm{Si}$ polymeric silsesquioxane and the monomer compound on thermal properties of 
epoxy nanocomposite. European Polymer Journal, 44, 1003-1011.

Crescenzi, V., Francescangeli, A., Segre, A. L., Capitani, D., Mannina, L., Renier, D., et al. (2002). NMR structural study of hydrogels based on partially deacetylated hyaluronan. Macromolecular Bioscience, 2, 272-279.

Crescenzi, V., Francescangeli, A., Capitani, D., Mannina, L., Renier, D., \& Bellini, D. (2003). Hyaluronan networking via Ugi's condensation using lysine as cross-linker diamine. Carbohydrate Polymers, 53, 311-316.

Dastjerdi, R., \& Montazer, M. (2010). A review on the application of inorganic nanostructured materials in the modification of textiles: Focus on anti-microbial properties. Colloids and Surface B: Biointerfaces, 79, 5-18.

Duan, Y., Jana, S. C., Lama, B., \& Espe, M. P. (2015). Self-crosslinkable poly(urethane urea)-reinforced silica aerogels. RSC Advances, 5, 71551.

Eslahi, N., Simchi, A., Mehrojoo, M., Shokrgozar, M. A., \& Bonakdar, S. (2016). Hybrid cross-linked hydrogels based on fibrous protein/block copolymers and layered silicate nanoparticles tunable thermosensitivity, biodegradability and mechanical durability. RSC Advances, 6, 62944-62957.

Haxaire, K., Maréchal, Y., Milas, M., \& Rinaudo, M. (2003). Hydration of polysaccharide hyaluronan observed by IR spectrometry. I. Preliminary experiments and band assignments. Biopolymers- Biospectroscopy Section, 72, 10-20.

Heinemann, S., Coradin, T., \& Desimone, M. F. (2013). Bio-inspired silica-collagen materials: Applications and perspectives in the medical field. Biomaterials Science, 1, 688-702.

Hill, D. J. T., Preston, C. M. L., \& Whittaker, A. K. (2002). NMR study of the gamma radiolysis of poly(dimethyl siloxane) vacuum at $303 \mathrm{~K}$. Polymer, 43, 1051-1059.

Hu, X., Li, D., Zhou, F., \& Gao, C. (2011). Biological hydrogel synthesized from hyaluronic acid, gelatin and chondroitin sulfate by click chemestry. Acta Biomaterialia, 7, $1618-1626$.

Huerta-Angeles, G., Brandejsová, M., Kulhánek, J., Pavlík, V., Smejkalová, D., Vágnerová, H., et al. (2016). Linolenic acid grafted hyaluronan: Process development, structuralcharacterization, biological assessing, and stability studies. Carbohydrate Polymers, $152,815-824$.

Jayes, L., Hard, A. P., Séné, C., Parker, S. F., \& Jayasooriya, U. A. (2003). Vibrational spectroscopic analysis of silicones: A fourier transform-raman and inelastic neutron scattering investigation. Analytical Chemestry, 75, 742-746.

Kotzianová, A., Rebícek, J., Pokorný, M., Hrbác, J., \& Velebný, V. (2016). Raman spec troscopy analysis of biodegradable electrospun nanofibers prepared from polymer blends. Monatshefte für Chemie-Chemical Monthly, 147, 919-923.

Lewandowska, K., Sionkowska, A., Grabska, S., \& Kaczmarek, B. (2016). Surface and thermal properties of collagen/hyaluronic acid blendscontaining chitosan. International Journal of Biological Macromolecules, 92, 371-376.

Lewandowska, K., Sionkowska, A., Grabska, S., \& Michalska, M. (2017). Characterisation of chitosan/hyaluronic acid blend films modified by collagen. Progress on Chemistry and Application of Chitin and Its Derivatives, 22, 125-134.

Liu, J., Detrembleur, C., De Pauw-Gillet, M. C., Jérome, C., \& Duguet, E. (2015). Gold nanorods coated with mesoporous silica shell as drug delivery system for remote near infrared light-activated release and potential phototherapy. Small, 11, 2323-2332.

Luan, Z., Fournier, J. A., Wooten, J. B., \& Miser, D. E. (2005). Preparation and characterization of (3-aminopropyl)triethoxysilane-modified mesoporous SBA-15 silica molecular sieves. Microporous and Mesoporous Materials, 83, 150-158.

Meléndez-Zamudio, M., Villegas, A., González-Calderón, J. A., Meléndrez, R., Meléndez-Lira, M., \& Cervantes, J. (2017). Study of a polydimethylsiloxane (PDMS) elastomer generated by $\gamma$ irradiation: Correlation between properties (thermal and mechanical) and structure (crosslink density value). Journal of Inorganic and Organometallic Polymers and Materials, 27, 622-632.
Peixoto, A. F., Fernandes, A. C., Pereira, C., Pires, J., \& Freire, C. (2016). Physicochemical characterization of organosilylated halloysite clay nanotubes. Microporous and Mesoporous Materials, 219, 145-154.

Peña-Alonso, R., Rubio, F., \& Rubio, J. (2005). The role of $\gamma$-Aminopropyltriethoxysilane $(\gamma$-APS) on thermal stability of TEOS-PDMS ormosils. Journal of Sol-gel Science and Technology, 36, 77-85.

Peña-Alonso, R., Rubio, F., Rubio, J., \& Oteo, J. L. (2007). Study of the hydrolysis and condensation of 3-aminopropyltriethoxysilane by FT-IR spectroscopy. Journal of Materials Science, 42, 595-603.

Qi, Y., Chen, L., Jiang, S., Yu, J., Yu, B., Xiao, C., et al. (2016). Investigation of silicon wear against non-porous and micro-porous $\mathrm{SiO} 2$ spheres in water and in humid air. RSC Advances, 6.

Sánchez-Téllez, D. A., Téllez-Jurado, L., \& Chávez-Alcalá, J. F. (2014). Bioactivity and degradability of hybrid nano-composites materials with great application as bone tissue substitutes. Journal of Alloys and Compounds, 615, S670-S675.

Sánchez-Téllez, D. A., Téllez-Jurado, L., \& Rodríguez-Lorenzo, L. M. (2015). Optimization of the $\mathrm{CaO}$ and P2O5 contents on PDMS-SiO2-CaO-P2O5 hybrids intended for bone regeneration. Journal of Materials Science, 50, 5993-6006.

Sánchez-Téllez, D. A., Téllez-Jurado, L., \& Rodríguez-Lorenzo, L. M. (2017). Hydrogels for cartilage regeneration, from polysaccharides to hybrids. Polymers, 9, 671.

Sánchez-Téllez, D. A., Téllez-Jurado, L., Rodríguez-Lorenzo, L. M., Mazo, M. A., Rubio, J., \& Tamayo, A. (2017). Surface effects on the degradation mechanism of bioactive PDMS-SiO2-CaO-P2O5 hybrid materials intended for bone regeneration. Ceramics International, 43, 476-483.

Sánchez-Téllez, D. A., Téllez-Jurado, L., \& Rodríguez-Lorenzo, L. M. (2018). Is your polymer smart enough? Better make a hybrid. In L. Peponi, \& J. M. Raquez (Eds.). How smart are the polymers? (pp. 335-354). New York: Nova Science Publishers, Inc.

Sun, Y., Yanagisawa, M., Kunimoto, M., Nakamura, M., \& Homma, T. (2016). Estimated phase transition and melting temperature of APTES self-assembled monolayer using surface-enhanced anti-stokes and stokes Raman scattering. Applied Surface Science, 363, 572-577.

Sun, Y., Yanagisawa, M., Kunimoto, M., Nakamura, M., \& Homma, T. (2017). Depth profiling of APTES self-assembled monolayers using surface-enhanced confocal Raman microspectroscopy. Spectrochimica Acta Part A, Molecular and Biomolecular Spectroscopy, 184, 1-6.

Tamayo, A., \& Rubio, J. (2010). Structure modification by solvent addition into TEOS/ PDMS hybrid materials. Journal of Non-crystalline Solids, 356, 1742-1748.

Tchobanian, A., Van Oosterwyck, H., \& Fardim, P. (2019). Polysaccharides for tissue engineering: Current landscape and future prospect. Carbohydrate Polymers, 205, 601-625.

Téllez, L., Rubio, J., Rubio, F., Morales, E., \& Oteo, J. L. (2003). Synthesis of inorganicorganic hybrid materials from TEOS, TBT and PDMS. Journal of Material Science, 38, 1773-1780.

Téllez, L., Rubio, J., Rubio, F., Morales, E. \& Oteo, J. L. (2004). FT-IR study of the hydrolysis and polymerization of tetraethyl orthosilicate and polydimethyl siloxane in the presence of tetrabutyl orthotitanate. Spectroscopy Letters, 37, 11-31.

Ullah, F., Javed, F., Othman, M. B. H., Khan, A., Gul, R., Ahmad, Z., et al. (2018). Synthesis and functionalization of chitosan built hydrogel with induced hydrophilicity for extended release of sparingly soluble drugs. Journal of Biomaterials Science Polymer Edition, 29, 376-396.

Zhao, W., Su, Y., Gao, X., Qian, Q., Chen, X., Wittenbrink, R., et al. (2017). Confined crystallization behaviors in polyethylene/silica nanocomposites: Synergetic effects of interfacial interactions and filler network. Journal of Polymer Science Part B, Polymer Physics, 55, 498-505. 